\title{
All change for the new regime
}

Received: 22nd August, 2000

\section{Margaret Craig}

graduated from Glasgow University in 1979 and has worked in the financial services industry ever since, specialising in pensions from day one. She has seen both sides of the fence, having worked in administration for an employee benefit corporation and later as an IFA. Margaret was with Standard Life for eleven years but is now Manager (Pensions Development) with Scottish Equitable, analysing and speaking on pensions issues and writing for the financial press. She has had a particular interest in the topic of pensions for women for several years now, writing articles in the financial press and speaking on the subject to a variety of audiences. At present the Government plans for pensions reform take up most of her working hours. Stakeholder is one example. Another is the introduction of pensions sharing on divorce - Margaret has been a member of the $\mathrm{ABI}$ joint working group on pensions and divorce for the past three years.

Abstract This paper will cover the legislation to be introduced in April 2001 bringing into force stakeholder pensions and the new defined contribution regime. It explains the legislation in some detail and also covers the implications for customers.

Keywords: State Second Pension (S2P); Stakeholder; the new defined contribution (DC) regime

\section{Introduction}

The introduction of Stakeholder next April will mean changes in the way the pensions industry advises its customers. But Stakeholder will not be the only option; it will be part of the new defined contribution regime. The changes to be introduced by the new regime will have advice implications for many customers, both individual and corporate extending well beyond just Stakeholder.

There are at least three areas where changing pension legislation will mean changes for customer advice:

- changes to State Pensions

- Stakeholder itself, and,

- the wider issues of the new defined contribution regime.

Margaret Craig

Scottish Equitable, Scottish Equitable House, Edinburgh Park, Edinburgh EH12 9SE.

Tel: 01315496217 ; Fax: 0131459 1144; e-mail:margaret.craig@ scoteq.co.uk

\section{Changes to State Pensions}

The current State Earnings Related Pension Scheme is due to be replaced in 2002 by the new State Second Pension
(S2P). The new scheme will provide better benefits than SERPS with the biggest impact being on lower earners. Those earning between the LEL and $\mathcal{E}^{9}, 500$ p.a. will be entitled to twice the level of benefit as SERPS would have provided for someone earning $£ 9,500$ p.a. For those higher up the earning ladder, S2P will offer increased benefits with the difference from SERPS, gradually levelling out until earnings reach $\mathcal{K}_{21,600}$ at which point benefit levels are the same. In addition, S2P will provide benefits for certain carers. A non-earner in receipt of any carer's allowance, or child benefit for a child under five, will be entitled to S2P benefits as if they were earning $£ 9,500$.

Changes to benefits raise the question of whether to save for your own retirement or rely on the State. In addition to the changes planned, the Government has already put in place a Minimum Income Guarantee (MIG) to ensure that no individual pensioner's income falls below a certain level, 
currently $\oint^{7} 78.45$ p.w. There is, therefore, concern that, particularly where contributions are low, some people could save for their own retirement only to find that they simply replace income which would otherwise have come from the State. This is made more problematic by the fact that the MIG is due for large step increases over the next $2-3$ years, while pensions increase in line with RPI, therefore creating the prospect of an ever-widening gap.

However, the Government has announced that it plans to introduce a 'Pensioner Credit' to ensure that people are not discouraged from saving for retirement. The consultation paper on this proposal was issued towards the end of last year and comments are to be with DSS by the end of February, 2001. Clearly it is too early to be confident of the detail which will eventually emerge. The current proposals would mean, broadly speaking, that those who have, say, a small personal pension would not lose out on state support entirely but would instead keep 60p in the $\mathcal{E}^{1}$ of their private income. It remains to be seen whether, assuming it goes ahead on this basis, this constitutes enough encouragement to save.

Customers will also need to consider whether they contract out. Contracting out has never been simple and, for many, it is about to get more complex. Once $\mathrm{S} 2 \mathrm{P}$ has been introduced, rebates for those earning up to $£ 21,600$ who contract out using personal pensions will increase, to reflect the higher benefits being given up.

For their counterparts who contract out via an occupational scheme (whether defined benefit or defined contribution) the situation is more complex. Essentially they will only partially contract out of what would have been the SERPS benefit and remain entitled to the difference between full S2P rights and SERPS benefits.

It is stating the obvious to say that this level of complexity clearly underlines the need for advice.

\section{Stakeholder pensions}

Now we turn to Stakeholder itself. Stakeholder, it is said, will be a simple, cheap, flexible product aimed at those who can afford to save for their own retirement but are not currently doing so.

The regulatory regime for selling Stakeholder will be rather different from that governing other pension products. The Financial Services Authority has confirmed that decision trees will be used as part of the non-advised stakeholder sales process. Prescribed by the FSA, the trees are intended to help prospective customers and will provide information, not advice.

Since decision trees offer information, staff who work in, say, a call centre environment talking customers through the trees will not need to be authorised to give advice. Adequate supervision arrangements for such staff will of course be required, since the line between information and advice can be easy to miss in some circumstances. In addition it is extremely likely that many customers will not appreciate the distinction between information and advice.

And many customers will continue to want advice, not just information. For example, customers may wish to take advice on whether or not to contract out. Others may want advice on the amount they should contribute or where to invest their contributions. Those who are already saving may need help to decide whether to continue with existing arrangements or make any changes.

It is not just individuals who may 
need advice. Many employers will be facing new responsibilities and may look for advice on how best to discharge them. The Stakeholder Regulations require all employers with no suitable current pension for employees, who have five or more employees, to 'facilitate access' to a stakeholder scheme. Employers have until 8th October, 2001 to comply with this requirement.

The employer must:

- consult his employees on the choice of stakeholder provider (the Regulations contain no details on how this is to be done so it would appear to be up to the employer to decide the form of the consultation)

- designate a stakeholder provider

- provide information about the scheme to his employees

- offer access to all his relevant employees (broadly speaking those earning more than the LEL, who are not members of an existing occupational scheme) once they have been employed for three months

- provide a payroll deduction facility for any employees who wish to contribute

- pass contributions on to the designated provider (within the same timescales as are currently laid down for money purchase occupational schemes).

The employer may contribute to the stakeholder scheme if he wants to, but is not required to do so.

If an employer already offers a pension arrangement, he may be exempt if the scheme he runs meets certain criteria.

Broadly speaking, where an employer runs an occupational pension scheme, he will be exempt if it is available to all employees (those under 18 or within five years of NRD may be excluded) and the waiting period to join is no more than 12 months.

If the employer offers a group personal pension, he will be exempt if the GPP is available to all his employees (excluding those under 18) within three months of joining work. The GPP must not impose exit penalties that go beyond recouping of normal loss. In addition, the employer must offer to make a contribution of at least 3 per cent of basic pay period earnings. This offer to contribute should be documented in the employee's contract of employment. The employer contribution can be made conditional upon a matching employee contribution of (no more than) 3 per cent of earnings. Where an existing GPP is set up on the basis of matching employer and employee contributions at a rate higher than 3 per cent, this can continue.

Advice issues for the employer will depend on what arrangement (if any) he currently offers but will include the following:

- offer Stakeholder or an alternative arrangement?

— which provider?

- will he contribute and if so, how much?

- to what extent will he actively encourage employees to join?

(Employers should tread warily here in case they cross the line between information and advice)

- what changes need to be made to existing arrangements (for example, should eligibility criteria be widened or employer contributions to a GPP be increased?)

- do different categories of staff need different arrangements?

Clearly, there are many areas where employers are likely to want advice on Stakeholder, particularly those who have 
never previously run any sort of pension arrangement for their staff.

\section{The new defined contribution regime}

The new defined contribution (DC) regime will cover Stakeholder, all new and existing personal pensions and money purchase occupational pension schemes which choose to adopt the new regime.

\section{Issues for individuals}

From April 2001, any UK resident regardless of earnings or employment status will be able to contribute (or have contributed on their behalf) up to \&3,600 p.a. into a DC contract. This will allow someone to fund a pension for their non-working partner. The

Regulations allow for third-party contracts so it will be possible for a parent, say, to take out a contract on behalf of a child. All contributions paid by individuals, regardless of employment status, will be paid net of basic rate tax.

Those who wish to pay more than f3,600 p.a. can base their contributions on the existing personal pension age/percentage related limits. The benefit basis for the new DC regime broadly follows the current personal pension basis. There will, however, be changes to life assurance and waiver of contribution benefit.

For contracts set up after April 2001, the maximum contribution allowable for life cover will be 10 per cent of the total pension contribution, rather than 5 per cent of Net Relevant Earnings. The concept of waiver is to be extended with providers permitted to cover risks like accident or unemployment.

Contributions paid for waiver will not attract tax relief, but, in the event of a claim, contributions may be paid net into the pension contract and obtain tax relief
Table 1

\begin{tabular}{llll}
\hline Year & Age & $\begin{array}{l}\text { Salary } \\
\boldsymbol{\Sigma}\end{array}$ & $\begin{array}{l}\text { Max. Contribution } \\
\boldsymbol{£}\end{array}$ \\
\hline 2001 & 42 & 60,000 & 12,000 \\
2002 & 43 & 20,000 & 12,000 \\
2003 & 44 & 20,000 & 12,000 \\
2004 & 45 & 30,000 & 12,000 \\
2005 & 46 & 40,000 & 15,000 \\
2006 & 47 & 40,000 & 15,000 \\
\hline
\end{tabular}

at that stage. Contracts in force before 6th April 2001 may continue on the current life assurance and waiver basis.

For personal pensions carry forward will be abolished and carry back simplified. (Rules for retirement annuities are unchanged.) The flexibility of earnings certification under the new regime may, to some extent, compensate for this loss. Contributions can be based on earnings certified in year 1 for a further five years even if earnings drop. If earnings rise, the individual may re-certify, creating a new basis year. Earnings related contributions can continue for up to five years after earnings cease altogether.

Consider the example in Table 1. Assuming this individual then stopped work altogether, they could continue to base their contributions on a salary of $£ 60,000$ for the next five years, after which their contributions would have to drop to $\mathcal{E}^{3}, 600$ p.a.

These changes to the rules will clearly have a significant impact on advice for customers!

\section{Issues for Money Purchase Schemes}

The changes will not only affect individual arrangements. The Trustees of Money Purchase Occupational schemes will have a one-off irrevocable option to convert their scheme to a new defined contribution regime scheme. Where a scheme does convert it moves from the existing benefit limit 
Table 2

\begin{tabular}{lll}
\hline \multicolumn{2}{c}{ Benefit Limit Regime } \\
\hline Defined Benefit Schemes & $\begin{array}{l}\text { Benefit Limit Money Purchase } \\
\text { Occupational Schemes } \\
\text { (CIMP, COMP, EPP) }\end{array}$ & Voluntary Contribution Schemes \\
& \multicolumn{1}{c}{ Contribution Limit Regime } \\
\hline \multirow{3}{*}{ Stakeholder Schemes } & $\begin{array}{l}\text { Converted Money Purchase } \\
\text { Occupational Schemes }\end{array}$ & Personal Pensions \\
\hline
\end{tabular}

regime to the new contribution limit regime outlined above.

This may not be a simple decision, since some members may be unable to move to the new regime (they may be overfunded) and for others it may not be good advice (if their benefits would suffer as a result).

Revised transfer Regulations will be introduced with a new test to be applied to check whether transfer is permitted. At the time of writing, the detail of the new transfer Regulations had not been finalised but it seems clear that there are likely to be more 'losers' than 'winners'. Controlling directors and those aged over 45 earning above 50 per cent of the earnings cap will be subject to a more stringent funding test than currently applies.

\section{Concurrency}

From April 2001 there will be two pension regimes, as shown in Table 2 .

Within each of these regimes, an individual may be a member of as many arrangements as he likes, provided he does not breach the relevant limits.

A limited form of concurrency between the two regimes has been agreed. Where an individual is earning

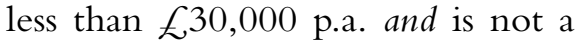
controlling director, they will be permitted to build up benefits under both regimes paying up to $\mathcal{K}^{3}, 600$ p.a. into a combination limit scheme. Benefits from the DC regime contract will be ignored when calculating maximum benefit under the benefit limit regime contract. This raises significant advice issues, particularly in relation to AVCs. People may favour stakeholder or personal pensions over an AVC because tax-free cash cannot be taken directly from an AVC. But AVCs can indirectly increase tax-free cash - and, in many cases, those individuals making AVCs will be earning more than $£ 30,000$ and therefore unable to contribute to stakeholder or personal pensions.

\section{Conclusion}

Taking an overall view, the changes being introduced in April 2001 are numerous, fundamental and far-reaching. The reason for these pensions reforms is to increase retirement savings in the UK. So while we work through the technical details and legal fine print, it is important not to forget that the real challenge is to work with these changes for the benefit of customers. 